\title{
İnsansız Hava Araçlarının Uçuş Süresinin Termal Hava Akımları Kullanılarak Arttırımı
}

\author{
Mehmet Konar ${ }^{1}$, Emin Tugay Kekeç ${ }^{2 *}$ \\ ${ }^{1}$ Erciyes Üniversitesi, Havacılık ve Uzay Bilimleri Fakültesi, Havacıllk Elektrik ve Elektroniği Bölümü, Kayseri, (ORCID: 0000-0002-9317-1196), \\ mkonar@erciyes.edu.tr \\ 2* Kapadokya Üniversitesi, Kapadokya Meslek Yüksek Okulu, Uçak Teknolojisi Bölümü, Nevşehir, (ORCID: 0000-0003-1530-996X), \\ tugay.kekec@kapadokya.edu.tr
}

(İlk Geliş Tarihi 4 Şubat 2021 ve Kabul Tarihi 4 Nisan 2021)

(DOI: $10.31590 /$ ejosat.874809)

ATIF/REFERENCE: Konar, M. \& Kekeç, E. T. (2021). İnsansız Hava Araçlarının Uçuş Süresinin Termal Hava Akımları Kullanılarak Arttırımı. Avrupa Bilim ve Teknoloji Dergisi, (23), 394-400.

$\ddot{O} \mathbf{z}$

İnsansız hava araçları (IHA), uzaktan komuta ya da otonom biçimde uçuş yapabilen içerisinde bir operatör bulunmayan hava araçlarıdır. İHA'lar askeri ve sivil amaçlar için geniş bir kullanım alanına sahiptir. Kullanım alanlarının geniş olması ile son kullanıcılar için pek çok farklı konfigürasyonlar ile tasarımı ve üretimi gerçekleştirilmektedir. Farklı konfigürasyonlar ile tasarlanan İHA sistemleri beraberinde birçok problemlerle birlikte gelmektedir. Geniş kullanım alanları ile İHA'larda karşılaşılan en temel eksiklik ise uçuş süresi ve menzilinin yetersiz olmasıdır. Bu problemin çözümü üzerine itki sisteminin iyileştirilmesi, aerodinamik iyileştirmeler, batarya teknolojisinde yapılan yenilikler gibi pek çok çalışma yapılmıştır.

Bu çalışmada İHA'ların uçuş süreleri ve menzillerinin iyileştirilmesi konu alınarak, termal hava akımlarından yararlanılmıştır. Termal hava akımları, güneş ışınlarının yeryüzünde bıraktı̆̆ etki ile oluşan yukarı yönlü yükselen hava akımları olarak tanımlanmaktadır. Yukarı yönlü hava akımlarının etkisi ile sportif hava araçları ve kuşlar herhangi bir itiş gücü ve enerji ihtiyacı olmadan havada saatlerce kalabilmekte ve uzun mesafeli olarak uçuş yapabilmektedir. Çalışma kapsamında termal hava akımları incelenmiş ve termal hava akımlarının otonom olarak tespit edilebilmesi için bir İHA sistemi tasarlanmış ve uçuşu gerçekleştirilmiştir. Uçuş denemeleri esnasında manuel ve stabilize uçuş modlarına göre termal hava akmlarının kullanımı ile yapılan uçuşta \%61 daha uzun uçuş süresi tespit edilmiştir.

Anahtar Kelimeler: İHA uçuş süresi, Termal hava akımları, Doğal taşıyıcılar, Planör.

\section{Increasing the Flight Time of Unmanned Aerial Vehicles by Using Thermal Air Currents}

\begin{abstract}
Unmanned aerial vehicles (UAV) are air vehicles that can be controlled remotely or fly autonomously, without an operator. UAVs have a wide range of uses for military and civilian purposes. With its wide range of usage areas, it is designed and produced with many different configurations for end users. UAV systems designed with different configurations come with many problems. The most basic deficiency encountered in UAVs with their wide range of use is the insufficient flight time and range. Many studies have been conducted on the solution of this problem, such as the improvement of the propulsion system, aerodynamic improvements, and innovations in battery technology.

In this study, thermal air current were used by taking the subject of improving the flight times and ranges of UAVs. Thermal air currents are defined as upward rising air currents caused by the effect of sunlight on the earth. With the effect of upward air currents, sports aircraft and birds can stay in the air for hours and fly long distances without any propulsion and energy need. Within the scope
\end{abstract}

\footnotetext{
*Sorumlu Yazar: tugay.kekec@kapadokya.edu.tr
} 
of the study, thermal air currents were examined and an UAV system was designed and flight was carried out in order to detect thermal air currents autonomously. During flight trials, $61 \%$ longer flight time was detected with the use of thermal air currents compared to manual and stabilized flight modes.

Keywords: UAV flight time, Thermal air currents, Natural carriers, Glider.

\section{Giriş}

İlerleyen mühendislik disiplinleri ile İHA sistemleri özellikle sivil kullanım sahalarında oldukça geniş bir sektörde yer bulmuştur. Havadan haritalama, tarım ve arama kurtarma ekipleri tarafından oldukça sık biçimde kullanılmaktadır. İHA'lar her geçen gün farklı yetenekler kazanmakta olmasına rağmen hava da kalış süreleri ve menzillerinde aynı ilerleme kaydedilememiştir. Uçuş süresinde artı̧ için batarya teknolojisi, aerodinamik iyileştirmeler ve itki sistemi üzerine çok fazla çalışma yapılmıştır [1-4]. Ek olarak yüksek verimli ve esnek solar paneller kullanılarak İHA tasarımı ve üretimi konularında çalışmalar yapılmıştır. Ancak solar sistemler kullanımda olan İHA sistemlerinin ekstra panel, batarya ve elektronik devreler ile İHA ağırlığı üzerinde olumsuz etkiler oluşturmaktadır [5-20].

İHA'ların uçuş süresi ve menzillerinde iyileştirme yapılabilmesi için termal hava akımlarının kullanımı konu alındığ kuşların uçuş stratejileri üzerine araştırma yapmıştır [10]. Çalışmada İHA'ların simülasyonlar ve gerçek uçuş sırasında irtifa kazanmaları için geliştirilmiş olan kontrol mekanizmalarını incelenmiştir. Ayrıca termal hava akımlarını kullanmak için yeni bir strateji önerisi oluşturmuşlardır. Diğer başka bazı çalışmalarda, termallerde otonom kullanımı üzerine yapılmıştır [21-22]

Termal hava akımlarının tespiti kadar termal içerisinde uygun yörüngede uçmakta oldukça önemlidir. Termalin merkezine yakın şekilde yapılan uçuşlar termal hava akımlarından en optimum düzeyde fayda sağlamaktadır [7]. Böylece termal içerisinde burun açısı, uçuş yönü ve hava hızı değerleri bilinmesi büyük önem arzetmektedir.

Termal hava akımları, güneş ışınlarının yeryüzü şekillerini 1sıtması ile meydana gelmektedir. Isınan yeryüzü şekilleri, hemen üzerinde varolan hava kütlesini 1sitarak yükselmesine sebep olmaktadır. $\mathrm{Bu}$ yükselen hava kütlesi aynı zamanda içerisinde bulunan cisimler üzerinde bir kaldırma kuvveti oluşturmaktadır. Oluşan termal hava akımı oldukça değişsen ve farklı parametrelere bağlıdır. Yeryüzü şeklinin biçimi, güneş ışınlarının gün içerisinde yeryüzü şekillerini ne kadar ısıttığı ve havadaki nem miktarı bu parametrelerden bazılarını oluşturmaktadır.

Kuşlar ve sportif hava araçları pilotları bu termal hava akımlarını kullanarak enerji harcamadan irtifa kazanabilmekte ve kazanılan irtifa ile süzülüş yaparak menzilini arttırabilmektedir. Termallerin konumu ve şiddeti ile ilgili bilgiler yamaç paraşütü, yelken kanat ve planör gibi hafif hava araçları pilotları tarafından tahmin edilebilmektedir.

$\mathrm{Bu}$ çalışmada termal hava akımlarının sabit kanatlı İHA'ların uçuş süresi ve menzillerine etkisi incelenmiştir. Çalışma kapsamında 2,5 metre kanat açıklığına sahip bir planör tibi İHA kullanılmıştır. İHA içersinde açık kaynak kodlu ve gelişmiş uçuş kontrol kartı Pixhawk Cube kullanılıştır. Bu kapsamda İHA otonom olarak termal hava akımlarını tespit etmekte ve termalin biçimine göre dairesel dönüşler yaparak irtifa kazanmakta ve kazanılan irtifa ile süzülerek enerji harcamadan uçuş yapabilmektedir. Stabil ve manuel modlarda yapılan uçuşlara göre \%61 gibi ciddi bir enerji kazanımı elde edilmiştir [8].

\section{Termal Hava Akımları ve Etkileri}

Termal hava akımları yeryüzünden, yükselen sıcak hava akımlarıdır. Bu hava akımları sayesinde bazı kuş türleri dairesel bir yörünge izleyerek kanat çırpmadan irtifa kazanabilmektedir. Böylece kuşlar büyük bir enerji harcamadan gökyüzünde saatlerce uçuş yapabilmektedir. Özellikle yırtıcı kuş türlerinden olan kartallar, atmacalar ve şahinler avlanmaları esnasında termal hava akımlarının enerjilerini yoğun şekilde kullanmayı başarabilmektedir. Bununla birlikte göç etmek isteyen kuş türleride termal hava akımlarından yararlanarak göç yolları üzerinde uzun süre durmaksızın uçuş yapabilmekte ve menzillerini arttırmaktadır $[11,12]$.

Termal hava akımları anlık hava şartları ve farklı arazi engebelerinde değişken güçlerde oluşabilmektedir. Termik olarakta anılan termal hava akımları her mevsim şartlarında oluşabilsede yoğun ve güçlü termikler genellikle yaz aylarında oluşmaktadır. Termikler neticesinde yukarı yönlü yükselen hava akımı içerisinde yeterli oranda nem taşırsa, yükselme ile birlikte su buharı yoğunlaşır ve kümülüs bulutları oluşabilmektedir.

Şekil 1'de termal hava akımları ile oluşan kümülüs bulutlarını ve planörlerin termal hava akımlarını nasıl kullandıklarına ilişkin temsili bir görsel verilmiştir. Şekil 1'e göre kümülüs bulutunun termal aktiviteler ile oluşum safhaları numaralı olarak verilmiştir. Safha 1'de Güneş, yer sıcaklığını artırmış ve daha sonra üzerindeki havayı 1sıttıktan sonra safha 2'de olduğu gibi yükselmeye başlamıştır. Yükselen hava sütunu daha sonra belirli irtifaya kadar yükseldikten sonra soğuyarak, safha 3 'te olduğu gibi genişlemiş ve aşağı yönde hareket gösterilmiştir. [10-14].

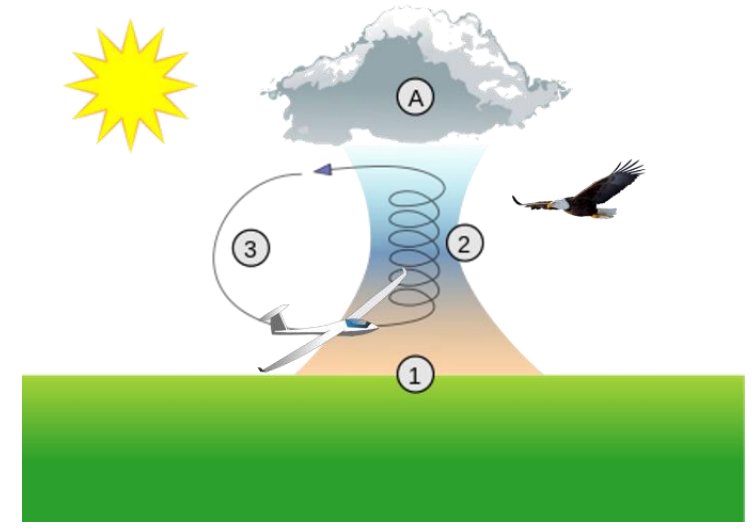

Şekil 1. Termal hava akımlarının gösterimi ve kümülüs bulutunun oluşumu

Çok hafif hava araçlarını oluşturan yelken kanat, yamaç paraşütü ve planör pilotları oluşan bulutları gözlemleyerek termal hava akımlarının tepe noktalarını gözlemleyebilmektedir. Ilıman iklim kuşağının yaşandığı bölgelerde yaklaşık olarak 3000 metre, çöl ve tropik iklim bölgelerinde 5000 metrenin 
üzerinde irtifalara kadar termal hava akımının etkisi gözlenebilmektedir [14].

Termal aktivitelerin oluşumlarını gösteren 3 temel etken vardır. $\mathrm{Bu}$ etkenler işaretler, kaynaklar ve tetikleyiciler olarak adlandırılmış ve Tablo 1' de detaylı olarak gösteilmiştir [15].

Tablo 1.Termal hava akımlarına etki eden etmenler

\begin{tabular}{|c|c|c|}
\hline İşaretler & Kaynaklar & Tetikleyiciler \\
\hline Bulutlar & Kasabalar & Sicaklık değişimi \\
\hline Kuşlar & Kuru alanlar & Orman kenarlar \\
\hline $\begin{array}{c}\text { Duman } \\
\text { hareketleri }\end{array}$ & Kayalıklar & Setler \\
\hline $\begin{array}{c}\text { Çok hafif hava } \\
\text { araçları }\end{array}$ & $\begin{array}{c}\text { Endüstriyel } \\
\text { alanlar }\end{array}$ & $\begin{array}{c}\text { Renk ve şekil } \\
\text { değişimi olan } \\
\text { bölgeler }\end{array}$ \\
\hline Hortum & Engebeli araziler & Bulut gölgesi \\
\cline { 2 - 4 } & Beton yapılar & Downdraft alanları \\
\hline
\end{tabular}

Termal hava akımları, değişken parametreler neticesinde farklı güçlerde oluşabilmektedir. Termal hava akımının gücü ise havacılık disiplinlerinde variometreler ile ölçülmekte ve 1-10 $\mathrm{m} / \mathrm{s}$ aralığında dikey hız ile belirtilmektedir. Dikey hız yeryüzünün güneş 1şınlarına ne kadar maruz kaldığı ve o günün hava şartları ile orantılı olarak değikenlik göstermektedir. Termalin gücüne ek olarak, havacılık için termal hava akımının genişliğide önem arz etmektedir. Çünkü termal hava akımının merkezi olarak bilinen çekirdek, termalin gücünün maksimum olduğu noktadır. Bu önemle hava araçları termal hava akımının içerisinde ideal bir dönüş açısı ile termalin merkezine yakın dönüşler yapmak istemektedir. Şekil 2'de termal hava akımı üzerinde dönüş yarıçapı ve tırmanma oranı ile hava aracının termal içerisinde izlediği güzergâh gösterilmiştir [14-15].

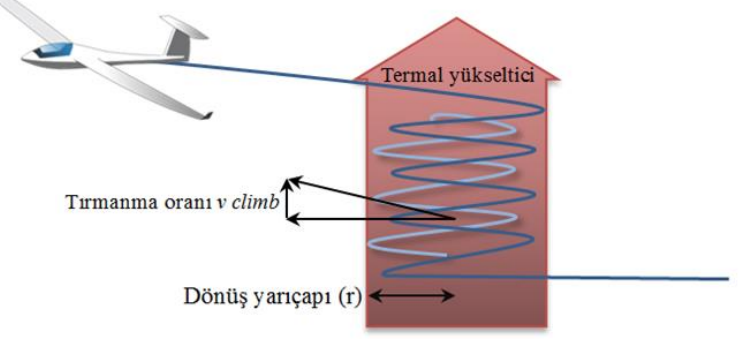

Şekil 2. Termal hava akımı içerisinde izlenen güzergâh

\subsection{Termal Hava Akımlarının Hava Araçları Üzerindeki Etkisi}

Termal hava akımları her zaman dilimi için farklı güçlerde yükselebilmektedir. Termal hava akımı içerisinde varolan hava kütlesi atmosfer boyunca belirli bir yüksekliğe kadar hareket edebilmekte veya inversiyon tabakası ile karşılaşarak yükselmeyi durdurabilmektedir. Genellikle yaz aylarında güçlü termal hava akımları oluşabilmekte ve inversiyon tabakasının kalınlığına göre bu tabakanın üzerine çıkabilmektedir [9, 14-16].

Atmosfer boyunca yükselen termal hava akımları, içerisinde uçan hava araçları, kuşlar ve bazı hafif nesneleri yükseltebilmektedir. Böylece herhangi bir itki sistemi olmayan planör, yamaç paraşütü veya yelken kanat gibi çok hafif hava araçlarını yüksek irtifalara çıkarabilir ve kilometrelerce uzak mesafelere süzülme firsatı tanır. Güçlü termal hava akımlarının oluştuğu aylarda, sportif hava aracı pilotları termal hava akımlarından faydalanarak mesafe (seyrüsefer) ve termik uçuşları yapmaktadır [14].

Termal hava akımlarının çekirdeği olarak bilinen merkez noktasında kaldırma gücü maksimum seviyededir. Pilotlar çekirdek etrafında, termal hava akımını kullanarak hızlı bir şekilde yükselmektedir [16]. Böylece içerisinde bulundukları termali en verimli şekilde kullanırlar. Pilotların termal hava akımı içerisinde dönmesi gereken ideal yarıçap Eşitlik 1'de verilmiştir.

$$
r=\frac{W}{S} \frac{2}{\rho g} \frac{\cos ^{2}(\gamma)}{\sin (\mu) C_{l}}
$$

Şekil 3 ve Eşitlik 1'e göre, r; dönüş yarıçap1, S; kanat alanı, $\rho$; hava yoğunluğu, $\mathrm{g}$; yerçekimi ivmesi ve $\mathrm{Cl}$ kaldırma kuvvetinin katsayısını vermektedir [9-10].

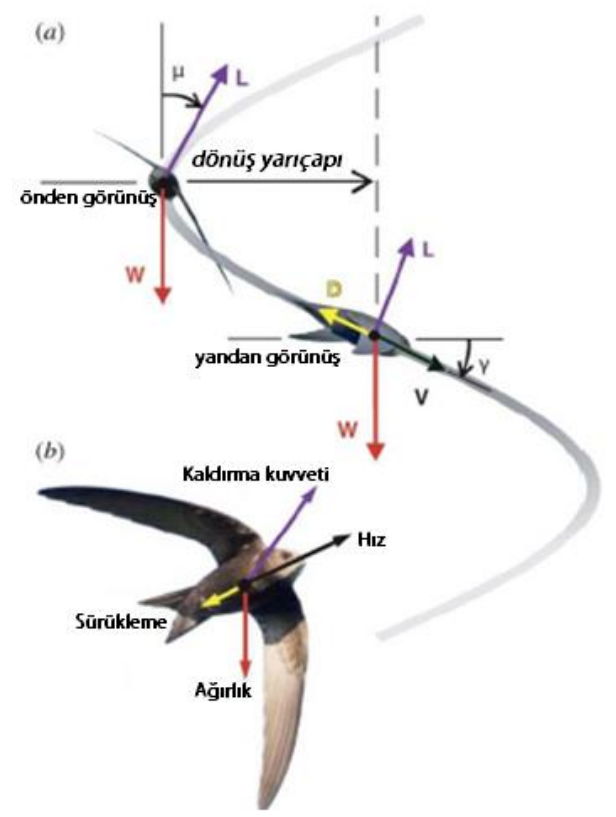

Şekil 3. (a) Termal aktivite içerisinde dönüş yarıçapı ve hücum açısının gösterimi (b) Temel kuvvetlerin gösterimi

Sportif havacılık pilotları için termal hava akımları tecrübeler ve belirli bilgi seviyesi ile kolaylıkla tespit edilebilsede bilimsel açıdan matematiksel eşitlikler ile termal hava akımlarının anlaşılması önem arz etmektedir. Bu önemle termal hava akımının gücü hava aracının ne kadar yükselebileceği ve kaç saniyede istenen irtifaya çıkabileceğini belirtmektedir. Ayrıca termal hava akımının genişliği, termalin içerisinde hangi açı ile dönüş yapılması gerektiğini göstermektedir. Ek olarak termal hava akımlarının çekirdeğinin tespiti hem sportif havacılık hemde İHA'lar için oldukça önemlidir. Bu çalışmada verilen eşitlikler İHA sistemleri için termal hava akımlarının anlaşılmasını ve daha optimum kullanımına yardımcı olmaktadır.

\subsection{Termal Hava Akımlarının Etkisinin Formülüzasyonu}

Termal hava akımları, güneş 1şınlarının yeryüzünü 1sıtmasıyla meydana gelen yükselen hava akımlarıdır. Isınan hava kolan şeklinde yükselir ve bu kolonun merkezinde 
kaldırma gücü en üst seviyededir. Sportif havacılıkta pilotlar bu merkeze yakın uçmak isterler. Çünkü merkeze ne kadar yakın bir uçuş yapılırsa pilotlar o kadar hızlı bir şekilde irtifa kazanacaklardır. Kaldırma gücünün en üst seviyede olduğu bu noktaya termal hava akımının çekirdeği denir. Eşitlik 2'de termal hava akımının herhangi $(\mathrm{x}, \mathrm{y})$ pozisyonundaki kaldırma kuvvetinin matematiksel ifadesi verilmiştir [9-10, 16].

$$
\omega(x, y)=W^{t h} \exp \left(-\frac{\left(x-x^{t h}\right)^{2}+\left(y-y^{t h}\right)^{2}}{R^{t h^{2}}}\right)
$$

Eşitlik 2'ye göre, $W^{\text {th }}$, termalin yatay enine alınan kesitine göre çekirdekteki dikey hava hızını $\mathrm{m} / \mathrm{s}$ olarak ifadesidir. $x^{\text {th }}$ ve $y^{\text {th }}$, çekirdeğin konumunu, $\mathrm{x}$ ve $\mathrm{y}$ termalin herhangi bir noktasındaki koordinatlarını göstermektedir. Ayrıca Rth ise termalin yarıçapını ifade etmektedir [16].

$\mathrm{Bu}$ çalışmada kullanılan uçuş kontrol kartı içerisinde barometre mevcuttur. $\mathrm{Bu}$ nedenle İHA ile yapılan uçuş testlerinde daha önce belirlenen irtifa değerinin üzerine çıkılması durumunda İHA motor gücü kapatılarak süzülüşe geçecektir. Bu süzülüş sırasında barometreden İHA'nın anlık olarak irtifasında yaşanacak bir değişiklik olursa, uçuş kontrol kartı bu bilgi ile bir dönüşe başlayacaktır. Bu dönüş çapı Eşitlik 2'ye göre uçuş kontrol kartı tarafindan hesaplanacak ve İHA kontrol yüzeylerini hareket ettiren servo motorlara iletilecektir. Daha önce de açıklandığı gibi termal hava akımları anlık olarak farklı bölgelerde ve farklı güçlerde oluşmaktadır. $\mathrm{Bu}$ nedenle bu işlemler kontrol kartı tarafından anlık olarak hesaplanmaktadır.

\section{Termal \\ Kullanımı}

Aktivitelerin

Tespiti

ve

Termaller güneş 1şınlarının yer yüzünü 1sıtması sonucu yükselen hava sütunlarıdır. Bu çalışmada tasarlanan ve üretilen İHA, sportif hava araçlarından olan planörlerin ölçekli modelidir. Çalışma kapsamında Şekil 4'te gösterilen $2540 \mathrm{~mm}$ kanat açıklığına sahip ASW 28 model RC planör kullanılarak uçuş kontrol kartı üzerinde yapılan değşiklikler ile termal hava akımlarından faydalanılmıştır.

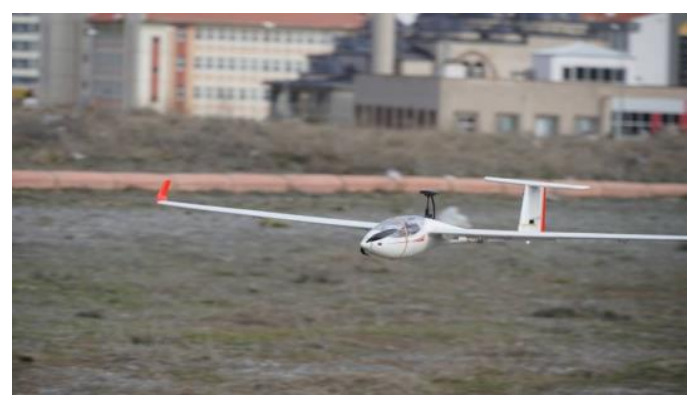

Şekil 4. ASW 28 model planör

$\mathrm{Bu}$ çalışma için ile Şekil 5'te belirlenen görev rotalarında sabit bir itiş gücü ile uçan İHA, önceden belirlenen irtifa aralıklarına gelince motor gücünü durdurarak termal hava akımlarını aramaya başlamaktadır. Bu irtifa aralıkları Pixhawk Cube kontrol kartına QGroundControl yazılımı aracılığıyla belirli parametre değerleri değiştirilerek yapılmıştır [9].

Pixhawk Cube kontrol kartı ile termal hava akımlarından yararlanmak için QGroundControl yazılımı ile yapılması gerekli adimlar sırasıyla;
- QGroundControl yazılımı aracılığıyla Way point'ler kullanılarak görev rotası oluşturulmalıdır.

- TECS (Total Energy Control System) parametreleri, QGroundControl yazılımı aracılığıyla giriş yapılmalıdır.

- İHA'nın L/D oranı bulunmalıdır. (Stabilize mod ile yapılan uçuşların kayıtlarından yararlanılarak oluşturulmuştur.)

- Termal hava akımı parametreleri ayarlanmalıdır.

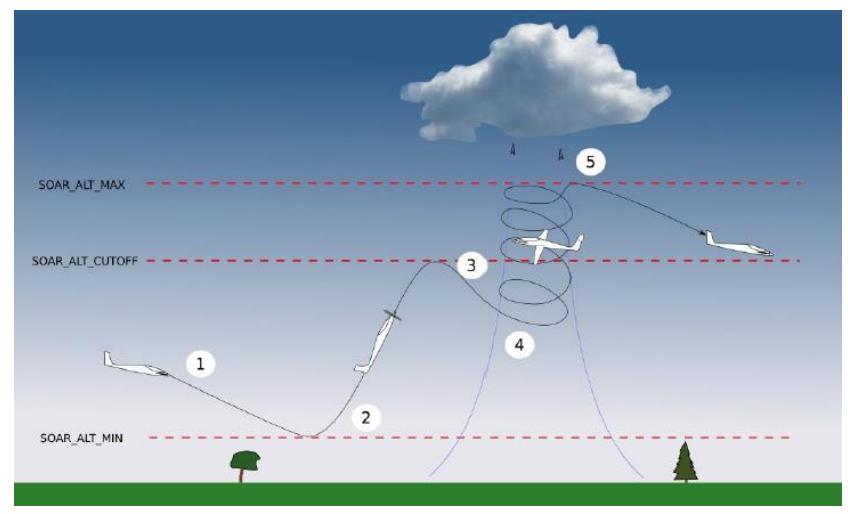

Şekil 5. İHA otonom termal arama işlem sürecinin gösterimi

Termal hava akımından yararlanmak için gerekli parametrelerden SOAR ALT MIN parametresi termal hava akımını aramaya devam edeceği minimum irtifayı belirtmektedir. QGroundControl yazılımı üzerinden görev rotası oluşturulurken, görev yapılmasiistenen irtifa SOAR_ALT_MIN değerinin üzerinde ayarlanmalıdır. Böylece termal arama görevi otonom olarak yapılabilecektir. SOAR_ALT_MIN parametresi için bu çalışmada en uygun değer, test uçuşlarında 80 metre olarak belirlenmiştir. Belirlenen irtifa değerinin altına indiğinde motor gücü otomatik olarak açılmakta ve SOAR_ALT_CUTOFF parametresi ile daha önceden ayarlanan irtifaya çıkmaktadır. SOAR_ALT_CUTOFF değerine çıktıktan sonra, İHA tekrardan motor gücünü kapatarak süzülüşe başlamaktadır. Süzülüş esnasında kontrol kartı içerisinde bulunan barometrik basınç sensörü ile irtifada oluşan değişiklikleri otomatik olarak değerlendirmektedir. Değerlendirme sonucunda irtifada anlık oluşacak artış termal hava akımlarının varlığını gösterecektir. Otonom biçimde tespit edilen termal hava akımlarından yararlanmak için İHA roll (yatış) hareketi ile termal aktivitesinin içerisinde belirlenen açı ile dönüş yapacaktır. Termal hava akımı içerisinde irtifa kazanan İHA, SOAR_ALT_MAX parametresi ile belirlenen irtifaya kadar yükselecektir. Başarılı bir tırmanışın ardından tekrar süzülüşe geçerek belirtilen görev bölgesi üzerinde uçuş gerçekleştirecektir [17]. Çalışma içerisinde termal hava akımlarının tespiti ve kullanımı için istenilen bütün parametreler Tablo 2' de detaylı olarak sunulmuştur [9].

Çalışmada süresince yaşanan en büyük zorluk termal hava akımlarının yerlerinin belirlenmesinde olmuştur. Çünkü termaller gözle tespit edilememektedir. Ancak anlık olarak barometrik basınç sensörü aracılığı ile tespit edilebilmektedir. Çalışma kapsamında Manuel, Stabilize, Altitude ve AUTO yani otonom uçuş modları ile test uçuşları yapılmıştır. Bu uçuşlar sonrasında, SD karta kaydedilen uçuş verileri alınarak, grafikler oluşturulmuş ve incelenmiştir.

Çalışmada otonom, manuel, stabilize modları ile yapılan tüm uçuşlar için Kayseri'nin Talas ilçesinde bulunan Model uçak pistinde denemeler yapılmıştır. Bu bölge düz bir arazi yapısına sahip ve yerleşim alanına uzak olmasından dolayı güvenlidir. Termal hava akımlarının tespiti ve kullanımı için yapılan görev 
uçuşu Şekil 6'da QGroundControl yazılımı ile planlanan rota uçuş kontrol kartına yüklenmiştir [9].

Tablo 2. QGroundControl yazılımı termal hava akımları için parametre listesi

\begin{tabular}{|c|c|}
\hline Parametre adı & Parametre açıklaması \\
\hline SOAR_ENABLE & $\begin{array}{l}\text { ArduSoar işlevini etkinleştirir veya devre } \\
\text { dış1 bırakır }\end{array}$ \\
\hline SOAR_VSPEED & $\begin{array}{c}\text { Termal arama moduna girip } \\
\text { girmeyeceğini belirleyen dikey hava hızı } \\
\text { eşiği }\end{array}$ \\
\hline SOAR_Q1 & $\begin{array}{l}\text { Termal güç için proses gürültüsünün } \\
\text { standart sapması }\end{array}$ \\
\hline SOAR_Q2 & $\begin{array}{l}\text { Termal pozisyon ve yarıçap için proses } \\
\text { gürültüsünün standart sapması }\end{array}$ \\
\hline SOAR_R & Gözlem gürültüsünün standart sapması \\
\hline SOAR_DIST_AHEAD & $\begin{array}{l}\text { İHA'nın termal merkeze olan mesafesinin } \\
\text { ilk tahmini }\end{array}$ \\
\hline SOAR_MIN_THML_S & $\begin{array}{l}\text { Uçağın, termal arama moduna girdikten } \\
\text { sonra, saniye cinsinden yükselmeye } \\
\text { çalışmasının minimum süresi }\end{array}$ \\
\hline SOAR_MIN_CRSE_S & $\begin{array}{c}\text { İHA'nın termal arama moduna girmekten } \\
\text { kaçınması gereken saniye olarak, } \\
\text { minimum süre }\end{array}$ \\
\hline SOAR_POLAR_CD0 & Kutupsal eğri parametresi \\
\hline SOAR_POLAR_B & Kutupsal eğri parametresi \\
\hline SOAR_POLAR_K & Kutupsal eğri parametresi \\
\hline SOAR_ALT_MIN & $\begin{array}{l}\text { Termal aramaya devam edilme sınır } \\
\text { irtifası }\end{array}$ \\
\hline SOAR_ALT_CUTOFF & $\begin{array}{l}\text { Termal aramaya otonom geçmek için } \\
\text { motor kapatma irtifası }\end{array}$ \\
\hline SOAR_ALT_MAX & Termal dönüşlerden çıkış irtifası \\
\hline
\end{tabular}

Planlanan görev noktaları Pixhawk Cube kontrol kartına yüklendikten sonra İHA Stabilize mod ile pilot komutasında kalkış yapmıştır. Güvenli irtifaya yükselen İHA pilot tarafından radyo vericisi üzerinden AUTO moda alınmıştır. Bu mod ile İHA rotada verilen ilk görev noktasına çıkmıştır. $\mathrm{Bu}$ nokta SOAR_ALT_MIN parametresinin (50 metre) üzerinde 150 metredir. Görev noktasına ulaştıktan sonra motor gücünü kapatmış ve süzülüşe başlamıştır. Ortalama 4 dakikalık süzülüş sonunda İHA 50 metreye alçalmıştır. İlk görev noktasında herhangi bir termal hava akımı tespit edilememiştir. İHA 50 metreye süzülen ikinci görev noktasına ulaşmak için tekrar motor gücünü açarak tırmanmaya başlamıştır. 150 metre yüksekliğe ulaşan İHA, tekrar motor gücünü kapatmıştır. Süzülüşe başlayan İHA'nın barometrik basınç sensörü aracılığıyla dikey hızında bir yükselme tespit etmiştir. Bu tespit ile İHA kontrollü biçimde dönüş hareketine başlamıştır. Şekil 7'de İHA'nın termal hava akımları içerisinde dönüşü gösterilmiştir. Kayıtlara göre 2,2 m/s vario değeri ve 13 metrelik yarıçapta dönüş manevrası ile başarılı bir biçimde termal hava akımınından faydalanarak irtifa kazanmıştır.

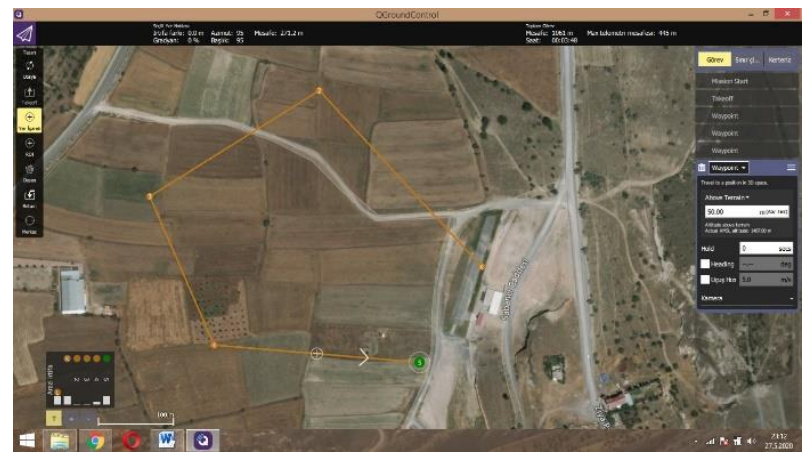

Şekil 6. Termal hava akımı tespit için rota planlaması

SOAR_ALT_MAX parametresi ile 250 metre olarak belirlenen termal limit irtifasına gelen İHA otonom olarak termal hava akımından ayrılmıştır. Motor gücünü aktif etmeden süzülerek daha önce belirlenen üçüncü görev noktasına ulaşmış ve tekrar termal arama görevi için süzülmeye başlamıştır. 1,5 $\mathrm{m} / \mathrm{s}$ yükseltme gücüne sahip termal hava akımını kullanarak 11 metre yaklaşık çapa sahip dönüşler ile irtifa kazanmış ve 65 metre yükselmiştir. Daha sonra dördüncü görev noktasına giderek pilot kontrolünde stabilize mod ile iniş yapmıştır. Şekil 8'de İHA'nın izlediği güzergâh sunulmuştur.

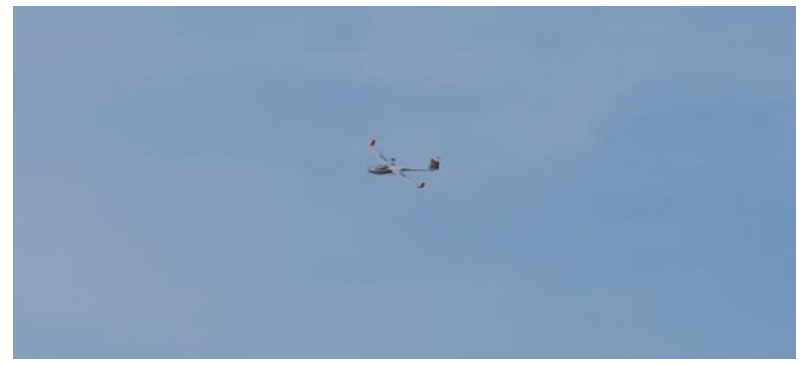

Şekil 7. İHA'nın termal hava akımı içerisinde dönüşü

Yapılan uçuş denemesinde yakalanan iki farklı termal hava akımı ile toplamda 18 dakika gerçekleştirilen uçuş için Şekil 9'da irtifa-zaman grafiği gösterilmiştir. Ayrıca İlk termal hava akımı içerisinde İHA'nın uçuş kayıtları incelenerek oluşturulan simülasyon ile elde edilen süzülüş rotası Şekil 10'da verilmiştir.

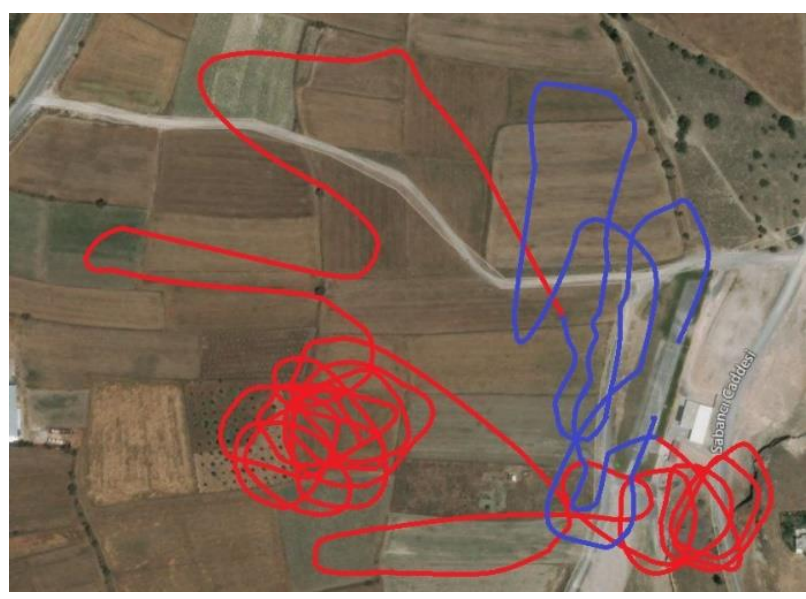

Şekil 8. Termal hava akım arama uçuşu boyunca İHA'nın izlediği güzergâh 


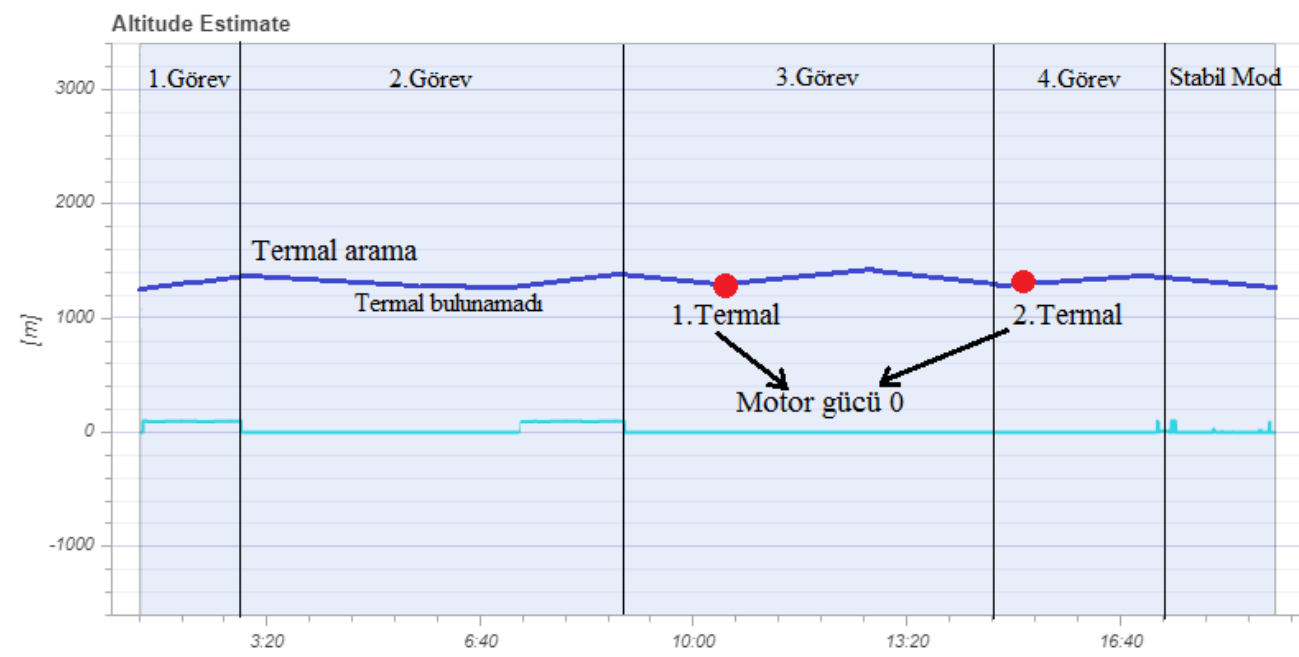

Şekil 9. Termal hava akımı için otonom uçuş irtifa-zaman grafiğgi

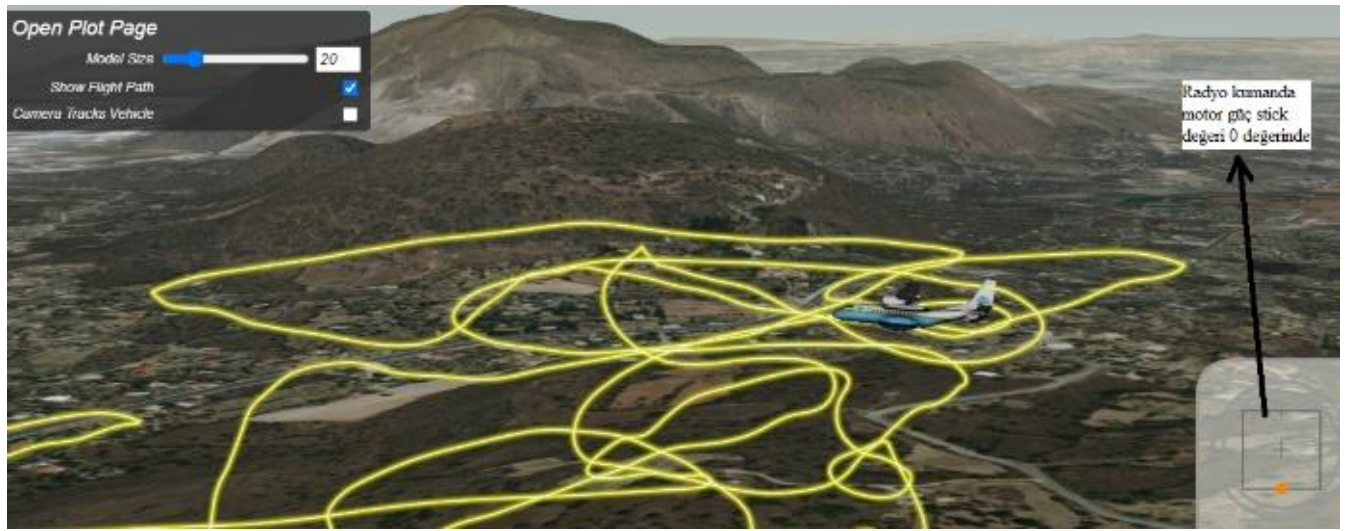

Şekil 10. Bulunan ilk termal aktivite içerisinde izlenen rota

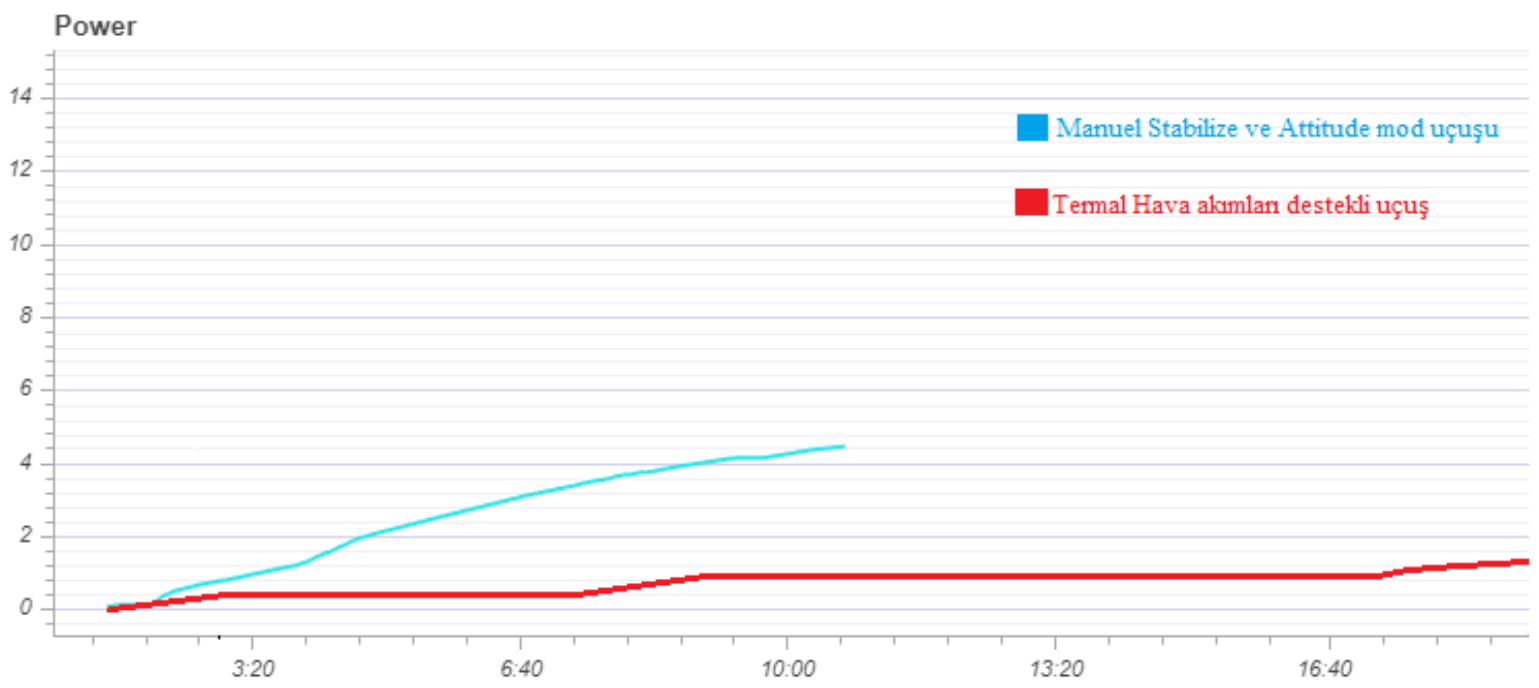

Şekil 11. İHA ile yapılan uçuşların batarya verileri karşılaştırma -zaman grafiği 
Termal hava akımlarından yararlanarak yapılan uçuşta yaklaşık 18 dakika havada kalabilen İHA inişten sonra Li-Po bataryasının sadece \%66,6'sını kullanmıştır. Aynı batarya ile Manuel, Stabilize ve Altitude mod ile toplamda 12 dakikalık uçuş neticesinde bataryanın yaklaşık olarak \%86'sını kullanarak iniş yapmıştır. Ayrıca Erciyes Üniversitesi Model Uçak pistinde serbest uçuş rotası sonucunda Manuel, Stabilize ve Altitude mod ile toplamda 3,61 km toplam menzil ile uçmuştur. İHA termal hava akımları kullanarak yaptığı uçuşta ise toplamda $4,87 \mathrm{~km}$ uçuş yaptığ 1 tespit edilmiştir. Her iki uçuş içinde bataryadan çekilen akım değerleri Şekil 11'de detaylı olarak sunulmuştur. Şekil 11'e göre Manuel, Stabilize ve Altitude mod uçuşları mavi renk ile simgelenmiş ve bataryadan devamlı bir enerji akışı olmuştur. Buna karşın termal hava akımlarından yararlanılarak yapılan uçuşta bataryadan anlık olarak çekilen enerjinin mavi renkli olarak gösterilmiş ve çok daha efektif bir enerji tüketimi tespit edilmiştir.

$\mathrm{Bu}$ çalışmada amaçlanan test uçuşlar başarılı bir şekilde gerçekleştirilmiştir. Uçuşlar sonucunda termal hava akımlarının İHA uçuş performansına ciddi ölçüde katkı sağladığı görülmüş ve ispat edilmiştir. Termal hava akımlarının etkisinin gözlenmesinde, farklı alanlarda, farklı hava araçlarıyla, yılın değişik zamanlarında uçuş testlerini yapılması faydalı olabilir.

\section{Sonuçlar}

$\mathrm{Bu}$ çalışmada güneşin yeryüzünü 1 sıtması sonucu ortaya çıkan termal hava akımlarının sabit kanatlı insansız hava araçlarının uçuş sürelerine ve menzillerine etkisi incelenmiştir. Ek olarak termal hava akımlarından yararlanabilen yüksek L/D oranına sahip bir ölçekli planör İHA prototipi geliştirilmiştir. İncelenen İHA ile değişik uçuş modlarında yalnızca batarya enerjisi kullanılarak test uçuşları yapılmıştır. Gerçekleștirilen test uçuşları neticesinde İHA'nın uçuş performansının iyileştirilmesi için uçuş verileri grafikler ile incelenmiştir.

Uçuş performansı artırılan İHA ile termal hava akımlarının tespit edildiği ve kullanıldığı farklı bir uçuş testi yapılmıştır. Bu uçuş testinde İHA'nın hem batarya enerjisi hem de termal hava akımlarının enerjisinin kullanılması ile menzil ve uçuş süresinde önemli ölçüde iyileştirme gözlemlenmiş̧ir. Termal hava akımlarından faydalanarak yapılan bir uçuşta, Manuel, Stabilize ve Altitude mod ile batarya enerjisi kullanılarak yapılan sıradan uçuşa göre, uçuş süresinde $\% 51,2$ artı̧ ve uçuş menzilinde ise \%43,8 artış elde edilmiştir. Bu artış ile termal hava akımlarının, sabit kanatlı İHA'ların uçuş sürelerine önemli katkılar sağladığını göstermiştir. Uçuş süresinde ve menzildeki daha fazla artışın gözlenmesi için, uygun mevsim koşullarında farklı arazi yapılarında uçuşlar yapılabilir. Çalışmadan elde edilen sonuçlara göre sabit kanatlı İHA üreticilerinin, tasarım süreçlerine yardımcı olacağı öngörülmüştür.

\section{Teşekkür}

$\mathrm{Bu}$ çalışma için Erciyes Üniversitesi Bilimsel Araştırma Projeleri Birimi tarafindan FYL-2020-9690 nolu proje tarafindan desteklenmiştir. Destekten dolayı teşekkür ederiz.

\section{Kaynaklar}

[1] Konar M., (2020). Simultaneous determination of maximum acceleration and endurance of morphing UAV with ABC algorithm-based model, Aircraft Engineering and Aerospace Technology, 92 (1), 579-586.

[2] Konar M. (2019). Redesign of morphing UAV's winglet using DS algorithm based ANFIS model, Aircraft Engineering and Aerospace Technology, 91 (9), 1214-1222.

[3] Shiau, J., Ma, D., Yang, P., Wang, G., Gong, H., 2009. Design of a solar power management system for an experimental UAV. IEEE Transactions on Aerospace and Electronic Systems, 45 (4), 1350-1360.

[4] Oettershagen, P., Melzer, A., Mantel, T. \& Rudin, K., (2015). A solarpowered hand-launchable UAV for low-altitude multi-day continuous flight. IEEE International Conference on Robotics and Automation ICRA, 3986-3993.

[5] Oettershagen, P., Stastny, T., Mantel, T., Melzer, A., Rudin,K., Gohl, P., Agamennoni, G., Alexis, K. \& Siegwart., R., (2016), Long-endurance sensing and mapping using a hand-launchable solar-powered UAV. 10th International Conference on Field and Service Robotics, 4 (3): 441-454.

[6] Goetzendorf-Grabowski, T., Frydrychewicz, A., Goraj, Z. \& Suchodolski, S. (2006), MALE UAV design of an increased reliability level, Aircraft Engineering and Aerospace Technology, 78 (3): 226-235.

[7] Zhu, B.J., Hou, Z.X. \& Ouyang, H. J., (2016). Trajectory optimization of unmanned aerial vehicle in dynamic soaring. College of Aerospace Sciences and Engineering, National University of Defense Technology, 3 (10): 1779-1793

[8] Kekeç, E.T., Konar, M. \& Oktay, T., (2019). Termal hava akımlarının sabit kanatlı hava araçlarının uçuş süresi ve menziline etkisinin incelenmesi, BILTEK uluslararası bilim, teknoloji ve sosyal bilimlerde güncel gelişmeler sempozyumu, Ankara, 476-481.

[9] Kekeç, E.T., (2020). Termal hava akimlarinin sabit kanatli hava araçlarinin uçuş süresi ve menziline etkisinin incelenmesi. Erciyes Üniversitesi, Fen Bilimleri Enstitüsü, Yüksek Lisans Tezi, Kayseri, 109s.

[10] Ákos, Z., Nagy, M., Leven, S. \& Vicsek, T., (2010), Thermal soaring flight of birds and UAVs, Bioinspiration \& Biomimetics , 5 (4): 312-328 .

[11] Buckland, G., (2012). Mastering Thermal soaring techniques. ( Web sayfası: http://www.orlandobuzzards.org/?page_id=1657), (Erişim tarihi: Ocak 2021).

[12] Scott, J., (2020). Birds, thermals and soring flight. ( Web sayfasi: http://www.aerospaceweb.org/question/nature/q0253.shtml ), (Erişim tarihi: Ocak 2021).

[13] Allen, M., (2006). Updraft model for development of autonomous soaring uninhabited air vehicles. In 44th AIAA Aerospace Sciences Meeting and Exhibit, Reno, Nevada,pp. 1510.

[14] Çamalan, İ., (2020). Soarıng ve termaller. ( Web sayfası: http://ibrahimcamalan.weebly.com/atpl-soaring.html), (Erişim tarihi: Ocak 2021).

[15] Akhtar, N., Cooke, A.K. \& Whidborne, J.F., (2012). A positioning algorithm for autonomous thermal soaring, Department of Aerospace Sciences, School of Engineering, 49 (2): 472-482.

[16] Tabor, S., Guilliard, I., \& Kolobov, A., (2018). ArduSoar: an open-source thermalling controller for resource-constrained autopilots, International Conference on Intelligent Robots and Systems (IROS), 215 (2): 6255-6262.

[17] Tabor, S., Guilliard, I. \& Kolobov, A., (2018). ArduSoar: an open-source thermalling controller for resource-constrained autopilots,: IEEE/RSJ International Conference on Intelligent Robots and Systems Conference, 10 (2): 6255-6262.

[18] Çoban, S. \& Oktay, T. (2018). Legal and Ethical Issues of Unmanned Aerial Vehicles. Journal of Aviation, 2(1), 31-35.

[19] Çoban, S. (2020), Autonomous performance maximization of researchbased hybrid unmanned aerial vehicle, Aircraft Engineering and Aerospace Technology, 92(4), 645-651

[20] Çoban, S. (2019). Different Autopilot Systems Design For a Small Fixed Wing Unmanned Aerial Vehicle. Avrupa Bilim ve Teknoloji Dergisi, (17), 682-691.

[21] Andersson, K., Kaminer, I., \& Jones, K. (2010). Autonomous soaring; flight test results of a thermal centering controller. In AIAA Guidance, Navigation, and Control Conference, 8034

[22] Andersson, K., Kaminer, I., Dobrokhodov, V., \& Cichella, V. (2012) Thermal centering control for autonomous soaring; stability analysis and flight test results. Journal of Guidance, Control, and Dynamics, 35(3), 963975 . 